\title{
IN VIVO OPTICAL CLEARING OF HUMAN SKIN UNDER EFFECT OF SOME IMMERSION AGENTS
}

\section{Maria Likhter ${ }^{3}$ (iD, Kirill Berezin ${ }^{1 凶}$ (D), Konstantin Dvoretsky ${ }^{2}$ (D), Gulnara Nuradenova ${ }^{4}$ (D), IImira Shagautdinova ${ }^{5}$ (I)}

\author{
${ }^{1}$ Saratov State University, Saratov \\ ${ }^{2}$ Saratov State Medical University, Saratov \\ ${ }_{3}^{3}$ Pavlov First Saint Petersburg State Medical University, Saint Petersburg \\ ${ }^{4}$ Astrakhan State Medical University, Astrakhan \\ ${ }^{5}$ Astrakhan State University, Astrakhan, Russia
}

\section{$\triangle$ berezinkv@yandex.ru}

ABSTRACT - Results of in vivo optical immersion clearing of human skin under the effect of aqueous solutions of a number of immersion agents (monosaccharides of ribose, glucose and fructose, as well as glycerol, a triatomic alcohol) were obtained with the use of the OCT method. Values of average velocity of scattering coefficient change, which were obtained through an averaged A-scan of the OCT signal in a derma region with the depth from 350 to $700 \mu \mathrm{m}$, were determined in order to evaluate the optical clearing efficiency. Good correlation was identified between the velocity of scattering coefficient change and the optical clearing potential value. Molecular modeling of interaction of a number of immersion clearing agents with collagen allowed to identify correlations between the optical clearing efficiency and the energy of intermolecular interaction.

\section{INTRODUCTION}

Applying modern methods of photomedicine and biomedical optics for diagnosis and therapy of diseases is associated with difficulties arising due to the fact that skin and many other biological tissues have strong scattering in visible and near-infrared regions. This scattering occurs due to deflection index change at borders of different macromolecular structures, mostly on collagen fibers that are primarily responsible for light scattering of skin [1]. These difficulties can be overcome with injection of biocompatible molecular agents into the tissue, which to some extent stimulates its optical clearing [2,3]. A lot of articles [4-10] present in vivo and in vitro experimental studies on clearing of different biological tissues, which indicates urgency of the issue. Papers [11-12] present studies on interaction of a number of immersion agents with collagen, conducted with the use of theoretical methods.

\section{EXPERIMENT METHODS AND RESULTS}

Aqueous solutions (60\%) of the following immersion agents were used to study optical clearing of skin: monosaccharides (ribose, glucose and fructose) and, for comparison, glycerol, a triatomic alcohol. The optical coherence tomography (OCT) was used to evaluate the effect of clearing properties of immersion liquids on skin in vivo experiments. Visualization was carried out with the use of an optical coherence tomograph Thorlabs OCP930SR (Thorlabs, USA) with the following parameters: radiation wave central length of $930 \pm 5 \mathrm{~nm}$., axial and lateral resolution of 6.2 and $9.6 \mu \mathrm{m}$. respectively (in the air), scan region length of $2 \mathrm{~mm}$. (Fig. 1).

The measurements were carried out on a skin area of the back of a forearm. The scans were recorded prior to exposure to the immersion agents, then at 1-minute intervals during 40 minutes of exposure. Four volunteers were involved in the measurements, and a total of five experiments was carried out for each immersion agent.

The attenuation coefficient $\mu \mathrm{t}[15]$ was evaluated by the OCT scans skew on the basis of the single scattering model [13-14]. The figure presents analyzed areas of the OCT image, an averaged A-scan of the OCT signal of the human skin dermal layer in vivo ( 5 minutes after the application of $60 \%$ ribose solution on the surface) and an approximating curve, which was plotted with the use of the single scattering model. OCT signals were averaged by the A-scan over the whole scanning area. The scattering coefficient values were determined in the averaged A-scan region at the depth from 350 to $700 \mu \mathrm{m}$.

In the scope of this paper, values of the light scattering coefficient, obtained with the use of the averaged A-scan in the derma region with the depth from 350 to $700 \mu \mathrm{m}$, were determined in order to evaluate the efficiency of in vivo optical clearing of human skin.

Values of the module of average velocity of the scattering coefficient change at the time segment from 5 to 35 seconds were used for numerical expression of the skin optical clearing efficiency. These velocities are presented in the table as skew values in regression line equations. The molecular modeling was carried out according to the method, described in paper [11] (Table 1).

As the table shows, the energies of interaction of a collagen peptide molecule with molecules of different 

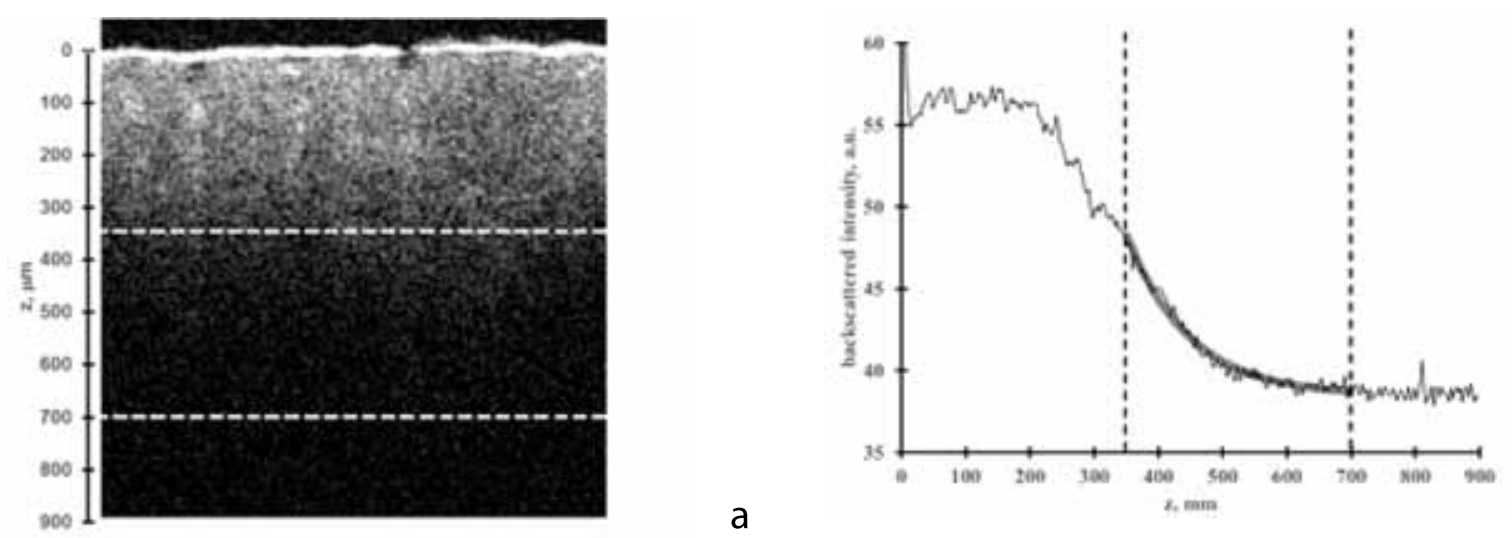

Fig. 1. Measurements of the scattering coefficient $\mu$ s in the derma region with the depth from 350 to $700 \mu$ m, based on the analysis of depth distribution of the averaged OCT signal with the use of the single scattering model; ( $a$ ) is the in vivo fragment of the B-scan of skin, used to average the OCT signal, (b) is the depth distribution of the averaged OCT signal (thin curve) and the approximation result according to the single scattering model (thick curve). The dashed lines are borders of the regions where the value $\mu_{s}$ was estimated

Table 1. Lengths of hydrogen bonds (in angstroms), energies of intermolecular inter-actions (in $\mathrm{kJ} / \mathrm{mol}$ ) between the fragments of collagen $(\mathrm{GPH})_{3}$ and different clearing agents, calculated with the use of the method PM6/B3LYP/6-31G(d), as well as experi-mental values of optical clearing velocity

\begin{tabular}{l|l|l|l}
\hline $\begin{array}{l}\text { Type of } \\
\text { agent }\end{array}$ & Hydrogen bond lengths & DE & $\begin{array}{l}\text { Efficiency of skin } \\
\text { optical clearing }\end{array}$ \\
\hline glycerol & $1.74 ; 1.91 ; 1.92 ; 1.93 ; 2.44$ & -42.8 & 0.607 \\
\hline ribose & $1.84 ; 1.90 ; 1.91 ; 1.95$ & -80.9 & 0.789 \\
\hline glucose & $1.68 ; 1.71 ; 1.84 ; 1.94$ & -94.5 & 0.937 \\
\hline fructose & $1.82 ; 1.84 ; 1.90 ; 1.96 ; 2.23$ & -89.2 & 1.056 \\
\hline
\end{tabular}

clearing agents, calculated with the quantum chemistry method, correlate well with the values of velocity of scattering coefficient change that were experimentally obtained within the present study.

It allows to speak of the fundamental importance of a post-diffusion stage, where collagen interacts with clearing agents and produces an effect on optical clearing of biological tissues. The study results allow to suggest that during the process of this interaction, a partial substitution of collagen-related water occurs. It leads to disturbance in a binding net of hydrogen bonds and, as a consequence, to a reversible process of collagen fibril dissolution, which, in its turn, lowers the value of their deflection index and equalizes it to the intercollagen medium. The higher collagen affinity of a clearing agent, the more effective is the process.

\section{REFERENCES}

1. Hirshburg J.M. Chemical agent induced reduction of skin light scattering: doctoral dissertation. / Texas A\&M University, 2009.
2. Tuchin V. V. Handbook of Optical Sensing of Glucose in Biological Fluids and Tissues / VV. Tuchin. - Taylor \& Francis Group LLC, CRC Press, 2009.

3. Tuchin V. V. Optical Clearing of Tissues and Blood. / PM 154, SPIE Press, Belling-ham, WA, 2006.

4. Genina E.A., Bashitatov A.N., Kochubey V.I., ET AL. // Optics and Spectroscopy, 2005. Vol. 98. No.3, p. 515-521.

5. Genina E.A., Bashkatov A.N., Sinichikin Yu.P., ET AL. / / Quantum Electronics, 2006. Vol. 36. No. 12, p. 1119-1124.

6. Bashiatov A.N., Korolevich A.N., TuChin V.V. et AL. // Asian Journal of Physics, 2006, Vol. 15 (1), p. 1-14.

7. Genina E.A., Bashkatov A.N., Tuchin V.V. // Adv. Optical Technologies, 2008, Vol. 2008, Article ID 267867.

8. Bashkatov A.N., Genina E.A., Tuchin V.V. et AL. // Laser Physics, 2009, Vol. 19(6), p. 1312-1322.

9. Wen X., Tuchin V.V., Luo Q. eT al. // Phys. Med. Biol., 2009, Vol. 54(22), p. 6917-6930.

10. Sudheendran N., Mohamed M., Ghosn M.G. ET AL. / J. Innovative Optical Health Sciences, 2010, Vol. 3(3), p. 169-176.

11. Berezin K.V., Dvoretsky K.N., Chernavina M.L. ET AL. // J. Mol. Modeling, 2018, Vol. 24(2), p. 45

12. BashKatov A.N., Berezin K.V., DVORETSKiY K.N. ET AL. // J. of Biomed. Opt., 2018, Vol. 23(9), p. 091416. https:// doi.org/10.1117/1.JBO.23.9.091416

13. Faber D.J., van der Meer F.J., Aalders M.C.G. ET AL. // Opt. Express, 2004, Vol. 12(19), p. 4353.

14. Lee P., Gao W., Zhang X. // Appl. Opt., 2010, Vol. 49(18), p. 3538.

15. Genina E.A., Bashkatov A.N., Kolesnikova E.A. ET AL. // J. Biomed. Opt., Vol. 19(2), p. 021109. https://doi.org/10.1117/1.JBO.19.2.021109 